\title{
Malaysian Agricultural: Conventional and Extended Thoughts
}

\author{
Pek Chuen-Khee \\ Department of Economics \\ Universiti Tunku Abdul Rahman \\ Selangor D.E., Malaysia \\ Tel: 6-012-682-3811 E-mail: pekck@mail.utar.edu.my
}

\begin{abstract}
The survival of the agricultural industry from the 1997 financial crisis attack ticks off the importance of this once 'sun-set' industry and the re-emphasis of its role as a growth catalyst to Malaysia. Agriculture, unlike the past, is no longer solely a food-based contributor but plays important non-food roles, which are multifunctional; economic, social, cultural and food security. This multifunctionality role of agriculture warrants sustainable development in the longer run. The current scenario of the Malaysian agricultural, specifically sustainable oil palm planting is deliberated against the negative claims of the world environmentalist. Extended thoughts on the possible ways of sustaining economic development through the idea of 'back to where you belong', equity and the possible changes of comparative advantage when ecology is considered, and efficiency and equity of ecosystem conservation are discussed.
\end{abstract}

Keywords: Agricultural multifunctionality, Sustainable development, Conventional and Extended thoughts

\section{Introduction}

The Brundtland Commission (1987) defines sustainable development as growth that "meets the needs of the present generation without compromising the ability of future generations to meet their own needs". As nations grow and standard of living rise, these needs become more complicated and expand into further dimensions. There has been growing consensus on the important linkage of environment and growth in the past years, especially in the context of sustainable agricultural as an aspect of economy growth and preservation of the ecological systems.

Why is agriculture unique to sustainable development, chiefly to the countries of ASEAN? The post-mortem of the 1997 financial crisis shows that agriculture is the only industry that could withstand the attack then. Agriculture continues to contribute to the growth of ASEAN not only in terms of Gross Domestic Product (GDP) but also job opportunities in terms of employment. The top three ASEAN countries whose GDP are highly dependent on agriculture is Lao PDR (more than 50 percent), Myanmar (45 percent) and Vietnam ( 24 percent). On the other note, this sector contributes towards 85 to 90 percent of the total employment in Lao PDR, 70 percent in Vietnam and 47 percent in Indonesia.

In Malaysia, these contributions by the agricultural sector are relatively lower. In terms of GDP, it contributes only approximately 8 percent and employment 16 percent. Malaysia has been more focused on the secondary and tertiary industries during the pre-financial crisis years but this 'sun-set' industry of agriculture has been re-emphasised of its role as a growth catalyst, resulting from the crisis post-mortem.

Sustainable development does not edged solely on environmental concerns but much more, which includes environmental sustainability, economic sustainability and socio-political sustainability. Environmental issues in agriculture basically relate to the dominance of agriculture with respect to natural resource use and its impact on the ecosystems. As discussed in the work of Jamal (2006), agricultural development requires the use of more land, water and chemical like fertilizers and others. Jamal found that a one percent change in the net export of palm oil leads to an increase of demand for land and agricultural chemicals by 0.25 and 0.3 percent respectively. In line with the aspiration of sustainable growth, the Malaysian government has only cleared old lands, but not virgin forest, to meet the demand for land in palm oil production. In addition, Azmi (2006) exerts that the country is aiming to lower the chemical inputs in tandem with the land management for palm oil use.

There are various legal and regulatory frameworks in Malaysia that governs the environmental and agricultural management to spur governance of sustainable growth like the National Agricultural Policy (NAP), Environmental Quality Act, National Environment Policy, National Conservation Strategy, National Forestry Policy, National Policy on Biodiversity and others. In the latest Third NAP, more focus has been given to the environmental aspect of agriculture employing two new strategic approaches, i.e. the agroforestry, and product-based approaches. The former approach aims at addressing the increasingly scarce resources like land while the latter approach is undertaken to reinforce and 
complement the agro-industrial development by strengthening the inter and intra-sectoral linkages including the development and expansion of intermediate and supporting industries.

Under the NAP3 new policy thrusts, strategies and implementation are focused on national considerations like food security, productivity, inflation, enhancing exports and reducing unproductive imports and sustainable use of natural resources. However, in this new policy there are still rooms for more consideration of the agricultural multifunctionality (AMF) dimension as a strategic tool in ensuring sustainable growth. AMF is defined as non-traded services provided by agriculture, known also as non-trade concerns (NTCs) in World Trade Organization (WTO) rules.

The European Union (EU), Switzerland, Japan and South Korea are enthusiasts of AMF who seek flexibility in tackling issues related to environment, social and rural development, and food security through agriculture and land-use in an integrated manner. However, the group of food exporting countries i.e. the Carins Group, which Malaysia and most of the ASEAN countries are members, throws much opposition and derision of the concept due to possible strengthening of protectionism under the guise of 'multifunctionality'.

This paper aims to discuss some of the conventional thoughts of sustainable environment and offer some extended thoughts on AMF. This hope can advocate further governmental discourse and intervention for a 'more AMF' agricultural management in the country.

\section{New Dimension- Agricultural Mutifunctionality}

The conventional manner of defining agricultural has evolutionalised from only a single role of food supply to multiple roles to include non-food benefits, better termed as AMF. These extended roles include the functions of economic, social, environment, food security and cultural. They blend well with the concept of sustainable development with calls for not only the environmental concerns but also environmental sustainability, economic sustainability and socio-political sustainability as discussed earlier. The followings are the discussion on those functions as extracted from the work of Jamal et al. (2006):

\subsection{Economic function}

This role relates to the direct economic benefits accrued to farmers from crop planting activities. Jamal found that average farm projects in his sampling site have had slight positive effects on agricultural income and consequently, on total income generation in 2004 and 2005 relative to the previous years.

\subsection{Social function}

This function is discussed in three different contexts, i.e.:

\subsubsection{Altruism value (AV)}

This is the benefit derived from the traditional sharing of wealth made possible through paddy plantation especially in the muslim community. In the same work, Jamal estimated the AV to be USD10.3 million.

\subsubsection{Employment opportunities}

Even though agriculture contributes only 16 percent of the total employment in the country, paddy plantation specifically, does play its role in the provision of employment. On average each hired labourer received payment of some USD 7.90 per day and aggregate returns per annum or the value of employment opportunity benefits is highly substantial at USD 31 million.

\subsubsection{Sheltering function (SF)}

This function is critically important in times of economic recession as a taker of excess or unemployed workforce from urban areas. In Malaysia, agriculture has successfully played this role during the 1997 financial crisis. The SF aggregate value during the entire crisis period from 1997-2000 stands at USD 126 million.

\subsection{Environmental function}

Alike the social function, this function is discussed in three different contexts, i.e.:

\subsubsection{Flood mitigation function}

Paddy fields are good rain water storage 'tanks' during the monsoon seasons, preventing floods in the nearby cities. Jamal asserted that this intangible value is one the most valuable contribution of paddy fields to the ecosystem. The estimated value of the flood mitigation function is approximately USD 0.034 million.

\subsubsection{Heat mitigation function}

Literatures show that paddy fields play an important role in heat mitigation. Empirical investigation found that USD 53,350 can be saved from the cost of cooling systems by the reliance of heat mitigation on the ecological function of paddy fields. 


\subsubsection{Air pollution reduction function}

Air pollution is one of the environmental problems in the country, much so with the presence of haze sent by the forest fires in the neighboring country, Indonesia during the dry seasons. Haze contains high density of dust particulate matter, $\mathrm{PM}_{10}$. During the hazy days, the $\mathrm{PM}_{10}$ concentration can reach up to $60 \mu \mathrm{g} / \mathrm{m}^{3}, 20$ percent higher than the standard level. Theoretically, air pollution in an area can be reduced with the presence of paddy fields, as the dust particles can be absorbed by the water retained in the fields. On average the state of Kedah, which is renowned for her paddy fields has lower Air Pollutant Index (API) reading than the more industrialized state of Selangor. Study has found that a total welfare improvement value of USD 2.03 million is accrued to the residents of Alor Setar, the capital city of Kedah state, due to the lower air quality resulted from the ecological functions of paddy fields.

\subsection{Food security}

This function of the AMF is to ensure adequate level of rice production in the country at all times for the ever increasing population. Report has found that with a simulation of 20 percent decline in rice production due to the liberalization of free trade, urban Malaysians are willing to pay (WTP) a price premium of 33 percent i.e. around USD 1 per month. As an aggregate the estimated value of this function is USD 9.2 million annually.

\subsection{Cultural function}

This cultural function is an addition to Jamal's selected functions. Like Japan and many other countries, Malaysia values agricultural activities and rural landscape dearly not only for commercial reasons like food exports and tourism but the cultural values they offer that help create strong communal bonds. Agricultural is a way of life to the Japanese as evident in the work of Goda, Kada and Yabe (2006) which talks about these amenities as the pride and 'brand name' of their hometowns. Autumn festivals as thanksgiving of good harvest and 'Obon' reunion time are still being practiced widely in Japan where family members return to their hometowns in the rural areas to worship their ancestors. In Malaysia, the Gawai Day celebrated in June annually by the Dayaks (natives of Sarawak state) is held for the similar reason of thanksgiving to God for good harvest. Every year crowds of tourists enjoyed themselves in this celebration which is uniquely 'agricultural-oriented'.

Acknowledging the increasing importance of these agriculture multifunctions, there are efforts in promoting these new dimensions in the country. Activities aim at inculcating more awareness and appreciation of the public are based on the objectives of making more multimedia awareness of AMF and a good example is the television advertisement of Sime Darby (the biggest oil palm producing company in the world), showing the importance of having sustainable palm oil production towards a more balanced growth.

These are important initiatives but may not be sufficient to drive more intervention from the government sector into recognizing AMF as a crucial element in sustainable development. The following sections discusses call for sustainable development (particularly in palm oil production) due to conventional reasons and offer some extended profound thoughts on AMF which may be worth deliberating.

\section{Issues towards sustainable development}

Currently in the country, the production of palm oil is faced with more sustainable issues than the plantation of other crops. There seems to be some mismatch of perception on the concern of sustainable growth in terms of land management used for oil palm plantation between the Malaysian government and international non-governmental bodies (NGOs). These NGOs and the Western countries are condemning Malaysia on the way forests are cut to make way for palm oil plantation especially in the Sabah state.

\subsection{The negative claims}

Statistics show that the land area in Sabah used for palm oil plantation has increased nearly 2.5 folds in 2004 (1,200,000 hectares) as compared to 1994 (500,000 ha) as quoted in Rahimatsah (2007). The NGOs perceives that the extension is through cutting of virgin forests. Jeffrey Sachs once claimed that Sabah is the most unique place on earth in terms of environmental and ecological endowments and he would like his future generations to have the equal opportunity to enjoy these gifts of nature. Therefore if more and more land is cleared via deforestation for palm oil production, the Sachs juniors may not been able to enjoy the bequest values of the ecosystems of Sabah that are very much appreciated by Sachs senior.

The conventional debates of sustainable development in palm oil production are not directly related or caused by the technological frontier but more of the concerns on the origin of the four million ha (2007) of land used as oil palm estates in the country. The idea of clearing forests for the sake of 'agri-commercial' reasons will affect the natural habitats of priceless animals and flora and fauna. The tigers, Sumatran rhinoceros, Asian elephants and orangutans are some of the very unique animals that are affected by land conversions for commercial uses. The Orangutans, especially, are faced with serious habitats problems and high possibility of extinction thanks to the estate expansion to reap high returns of palm oil in the world market. 
The other critical concern is the destruction of peatlands, which is crucial 'carbon sink' and 'water retention' role player. Land clearing for agricultural use will see peatlands tidied commonly through the traditional method of burning which releases huge concentration of carbon dioxide into the air due to the 'carbon sink' role of the peatlands. Evidently, during the 1997 Indonesia forest fires which see many peatlands destroyed and responsible for the vast increase of world carbon dioxide levels, an estimated 0.81 to $2.57 \mathrm{Gt}$ of carbon was released and that was equivalent to $13-40$ percent of the amount released by fossil fuel burning globally.

\subsection{The real scenario}

Commercial profits aside, the Malaysian government is dismissing all these baseless allegations as the country values highly and is a staunch devotee of sustainable development. The land areas used for palm oil production are from old logging areas or unproductive forests rather than the virgin rainforests as claimed. Tan et al. (2007) asserted that 64 percent of total land mass in Malaysia is rainforests as compared to United Kingdoms (UK) with a mere 12 percent. In addition to that, oil palm plantations only occupied 10 percent of the total mass land in the country. Besides, the government aims to plant 500,000 ha of forest plantation, double the existing ones in the states of Johor, Pahang, Sabah and Sarawak. So, if Malaysia is to be charged guilty in 'raping' the virgin rainforest, what about UK?

In the same work of Tan et al., it was reported that from 1990 to 2005, there was only less than one million ha of new land being converted into palm oil estate, but not as massively claimed by the west. In this study, it was also suggested that oil palm plantations are more effective than rainforests in playing the role of 'carbon sink' in terms of assimilation of dry matter per ha per year. Several studies indicated that biodiversity of flora and fauna in oil palm estates are not only stably unaffected but has attracted many species of birds, butterflies and mammals, notably even rare species like leopard cats.

A caucus "Roundtable on Sustainable Palm Oil" (RSPO) to promote the growth and use of sustainable palm oil and forging stronger co-operation within the supply chain and other stakeholders was established in 2004. Malaysia as one of the founding members is actively participating in managing RSPO activities and committing herself to the RSPO Principles and Criteria (e.g. transparency of management, commitment to long-term economic and financial viability, responsible in conservation of natural resources and biodiversity and others) to ensure sustainable palm oil production. Sustainability in palm oil is analogous to sustainability in the Malaysian agriculture due to its position as the number one agricultural crop in the country.

Complementing the RSPO is the Best management practice (BMP) that has been implemented and practiced in the country as initiatives towards agricultural sustainability. Operations from harvesting to production of oil palm products have been carried out consistently with the best approaches. Integrated pest management, use of organic fertilizers (from palm oil's empty fruit brunches), zero open burning and planting of leguminous crops (to minimize soil erosion) are some of the BMP.

\section{Extended thoughts- the unconventional philosophy}

The conventional concern of orangutans extinction in Malaysia may be relatively trivial if compared to the broader picture of long term optimality of resource use with limited agricultural land in the country. It is argued that the extinction of animals or plants species is still within the human tolerance level as many of such species like dinosaurs have been extinct from the world with not much externality been sacrificed or endured by mankind. But humans will be more greatly affected if one's country specifically, or the world generally, cannot sustain the supply of resources due to lack of suitable or productive crop land, and damaged ecosystems. It is an issue of vulnerability of the entire Malaysian economy and society.

While governmental and NGOs efforts and initiatives are mounted to address this problem, some extended thoughts are offered in this paper to re-look at agricultural sustainability beyond the conventional manner and consistent with AMF. The concept of extended comparative advantage and efficiency vs equity will be discussed in the following sections with the aim of addressing the vulnerability issue.

\subsection{Back to where 'you' belong}

The idea of planting crops only in their country of origin may be worth pondering. Famous street trees in Pretoria and Johannesburg named the 'jacarandas' are under threat as they are either to be felled or prevented from regenerating. Why bother about street trees? It has been claimed by some ecologists that jacarandas are invasive and would harm the biodiversity of the surroundings they inhibit. These trees are not domestically-originated, akin 'white-immigrant' from tropical and subtropical regions of South and Central America, Mexico, and the Caribbean, and hence they will draw more ecological resources to grow than the other native tree species. The continuation of planting jacarandas will lead to environmental resource inefficiency which is deteriorating to other local tree genus.

\subsection{Extended comparative advantage}

The ecological inefficiency caused by the jacarandas may shed some lights in broadening our thought in reassessing the concept of comparative advantage by David Ricardo. The principle of comparative advantage rests on the opportunity 
cost of production rather than the absolute cost. The opportunity cost of production of a good can be measured in terms of the production unit of another good need to be reduced to increase production by one more unit.

The principle of comparative advantage shows that even if a country has no absolute advantage in any product (i.e. cost of productions are higher in all goods as compared to the other country), the country can still specialized and export the product for which she has the lower opportunity cost of production. However, in comparative advantage, only financial costs are considered. The non-financial costs, more known as non-market values, are left out.

With the call for sustainable development and advancement of non-market valuation methodologies, it is timely that the environmental impacts of specializing and producing a good or service be reflected in the total cost of production. The valuation of these non-financial values of ecosystems can be estimated using valuation techniques like the contingent valuation and choice model. The incorporation of these environmental values change the total cost of production and possibly alters the specialization of goods that a country should produce. A simple simulation is discussed to demonstrate this likelihood.

Assuming two countries, country $\mathrm{M}$ and $\mathrm{N}$, share similar climate characteristics and are able to grow both crops, i.e. palm oil and paddy. Country M has more mountains and hilly lands than country N. The costs of producing one tonne of palm oil and paddy are USD 450 and USD 800 respectively in country M. In country N, they cost USD 600 and USD 1000 per tonne correspondingly. If absolute cost is considered, country $\mathrm{M}$ is more cost effective than country $\mathrm{N}$ in the production of both crops. However, comparative advantage shows that country M pays equal cost to produce 0.56 tonne of paddy as for one tonne of palm oil, while in country $\mathrm{N}$, production cost of one tonne of palm oil is equivalent to 0.60 tonnes of paddy. The opportunity cost criterion says that country $\mathrm{M}$ should specialize and export palm oil while $\mathrm{N}$ should go for paddy. This specialization is based on the conventional comparative advantage which takes into account solely the financial costs.

The extended comparative advantage which considers the non-market values in the process of identifying which country specializes in which crop production may give a different outcome. In country $\mathrm{M}$ since there are more hilly lands than country $\mathrm{N}$, clearing those lands for palm oil planting creates soil erosion which is costly to the environment. Unlike palm oil, planting paddy on hilly lands is not only safe but enhances the ecosystems. However, forest cutting is inevitable for cultivation of both crops. The environmental impact in planting palm oil is higher than paddy in country M. Assuming the reverse is true in country $\mathrm{N}$ as palm oil estates are more environmental friendly than paddy fields in terms of the carbon sink role they play.

Thus, these extra non-financial costs are to be calculated into the total production of those crops. Assuming non-market valuation techniques derived the environmental costs per tonne to be USD 550 for palm oil and USD 150 for paddy in country M and USD 200 and USD 650 for the same corresponding crops in country N. Table 1 and 2 show the possible changes in total cost of production, the opportunity costs of production and specialization when non-financial costs are reflected.

This simple example illustrates the possible change in specialization by both countries which share similar climatic background. This may offer a pointer for economists and countries to call for a worthy re-evaluation of crop production specialization to minimize long-term environmental impacts of crops from foreign land planted in local soils. This standpoint may be possibly valid as an extension from the prior discussion, i.e. "That palm oil should afterall not suitable to be planted in Malaysia but shall leave it to the countries of West Africa like Nigeria to grow as a native land of palm oil."

If the call to stop jacarandas from regenerating in Pretoria makes sense to us because it is invasive and environmentally unfriendly, then the notion of "Back to where 'you' belong" seems right. Malaysia should allow Nigeria to plant palm oil while concentrate on paddy production with equivalent commercial lost being compensated from the potential "palm oil market", which is similar to the carbon market created to trade carbon emissions and compensate disadvantaged countries. On the other hand if Malaysia chooses to continue with her production of palm oil then some form of compensation should be paid to the 'market' for damage on ecological systems of the country accrued to palm oil plantation. This will make sustainable development in the context of AMF more realistic and feasible.

\subsection{Efficiency and Equity}

The issue of sustainable development is a question of efficiency in ecological management. Malaysia as a resource rich nation is always the focal point of discussion when comes to natural resources sustainability. World bodies are exerting pressure on the country to preserve and conserve as many rainforests as possible but they never talk about who should be paying for all these resource maintenance costs. For a developing country like Malaysia to maintain her forest areas bearing in mind that 65 percent of land are covered by rich and dense tropical forests is a mouthful and enduring mission.

There are several world renowned national parks in the country like the National Park, more known as Taman Negara, Bako National Park, Gunung Mulu National Park and others that require huge conservation funds from the state governments. Taman Negara, the world oldest tropical rainforest is mostly located in the relatively poorer state of Pahang, 
whom pays for the conservation of the park. On one hand the state needs to be efficient in natural resources management but on the other hand the issue of social equity has to be addressed. Who shall pay these costs? It looks like the West and environmental NGOs value these parks more than the locals and as such these parks are open to probable development for commercial reasons in the future when funds are inadequate and growth for the quest of money dominates the passion for environmental services. It will not be surprising that a day will come where Taman Negara is developed by the Pahang state government for economic growth related motives.

At this juncture, the paper aims to highlight the need for a biodiversity market to create a world trust fund that would aid the high conservation costs of national parks in the country. The fund can channel monetary aids to the state government to ensure ling-term sustainability of those parks which are dearly valued by the world. Chichilnisky, who proposed and wrote the global trading of carbon emissions with preferential treatment for poor countries which became part of the Kyoto Protocol adopted by 166 nations in December 1997, noted in her environmental sustainability conference lecture at Monash University Malaysia in December 2007 that she is working on a similar model for biodiversity market. With this market in place in the near future it will be excellent to see preferential treatment being given to the developing countries like Malaysia to preserve the ecological assets for long term sustainable growth in tandem with AMF. With the issue of equity probably resolved with the creation of the biodiversity market, efficiency in the world environmental management is made more feasible.

\section{Conclusion}

This paper aims to offer some unconventional philosophy of looking at the issue of sustainable development in the light of AMF on top of the traditional views.

Acknowledging the importance of AMF, this study calls for more intervention from the government and NGOs to ensure sustainable growth. The scope of addressing this issue is broaden into three extended thoughts of "Back to where 'you' belong", extended comparative advantage and the struggle between environmental efficiency versus equity.

These thoughts shed some lights on the possibility of re-addressing the specialization of goods produced in a country when non-financial costs are considered. This may help to reduce and minimize energy extraction from nature used to grow crops which are more environmental-friendly when grown in native lands than foreign soils.

The issue of efficiency and equity has to be resolved in order to ensure the sustainability of ecosystems and biodiversity. The call for the setting up of a biodiversity market is timely to conserve the natural assets located in the land of poor or developing countries.

In short, new thoughts on addressing the issue of sustainable growth are essential and worth for deliberation. Though this paper offers limited insights regarding the notions of extended comparative advantage and efficiency and equity, nevertheless it drives some motivation for future researches.

\section{Special acknowledgement}

The author would like to accord credits to Professor Dr Jamal Othman of National University of Malaysia for his brilliant idea sharing of extended thoughts of sustainable development, and Professor Ryohei Kada of Yokohama National University, for his sharing of agricultural multifunctionality during his visit to Malaysia in February 2008.

\section{References}

Azmi, M. A. (2006). Overview of agriculture in ASEAN member countries. Final report Country case studies on multifunctionality of agriculture in ASEAN countries, The ASEAN Secretariat and MAFF Japan. Jakarta, 2006.

Goda, M, Kada, R. \& Yabe, M. (2006). Concept and significance of multifunctionality of agriculture: A global perspective. Final report Country case studies on multifunctionality of agriculture in ASEAN countries, The ASEAN Secretariat and MAFF Japan. Jakarta, 2006.

Jamal, O. (2006). New dimension for Malaysian agriculture amidst industrialization. Seminar proceedings of Multifunctionality and Revitalization of Agriculture. Editor: Ai Dariah et al. Indonesian Ministry of Agriculture, MAFF Japan and ASEAN Secretariat. Jakarta, 2006.

Jamal, O., Nousa, N. \& Arifin, T. (2006). Rural viability and environmental functions in Malaysian agriculture. Final report Country case studies on multifunctionality of agriculture in ASEAN countries, The ASEAN Secretariat and MAFF Japan. Jakarta, 2006.

Rahimatsah, A. (2007). Oil palm and conservation in Malaysia: Experiences from Sabah. Second symposium on sustainable resource development in Brussels, 28 March 2007.

Tan, K. T., Lee, K. T., Mohamed, A. R. \& Bhatia, S. (2007). Palm oil: Addressing issues and towards sustainable development. Renew Sustainable Energy Reviews. Doi:10.1016/j.rser.2007.10.001 (Article in press). 
Table 1. Total cost of production (financial costs only) and specialization

\begin{tabular}{|l|l|l|l|}
\hline Country & $\begin{array}{l}\text { Palm oil } \\
\text { USD/tonne }\end{array}$ & $\begin{array}{l}\text { Paddy } \\
\text { USD/tonne }\end{array}$ & Opportunity cost \& specialization \\
\hline $\mathrm{M}$ & 450 & 800 & $1: 0.56 /$ Palm oil \\
\hline $\mathrm{N}$ & 600 & 1000 & $1: 0.60 /$ Paddy \\
\hline
\end{tabular}

Table 2. Total cost of production (financial \& non-financial costs) \& specialization

\begin{tabular}{|l|l|l|l|}
\hline Country & $\begin{array}{l}\text { Palm oil } \\
\text { USD/tonne }\end{array}$ & $\begin{array}{l}\text { Paddy } \\
\text { USD/tonne }\end{array}$ & Opportunity cost \& specialization \\
\hline $\mathrm{M}$ & $1000(450+550)$ & $\begin{array}{l}950 \\
(800+150)\end{array}$ & $1: 1.05 /$ Paddy \\
\hline $\mathrm{N}$ & $800(600+200)$ & $1650(1000+650)$ & $1: 0.48 /$ Palm oil \\
\hline
\end{tabular}

